УДК 316

10.17213/2075-2067-2020-6-54-61

\title{
ТРАНСПРОФЕССИОНАЛИЗМ В СИСТЕМЕ ПРОФЕССИОНАЛЬНОЙ ПОДГОТОВКИ И АДАПТАЦИИ МОЛОДЫХ УЧЕНЫХ В УСЛОВИЯХ МОБИЛЬНОГО МИРА ${ }^{1}$
}

\author{
(C) 2020 г. О. С. Иванченко
}

\section{Южнн-Российский государственный политехнический университет (НПИ) имени М. И. Платова, г. Новочеркасск, Россия}

Цель исследования. В данной статье актуализируется проблема транспрофессионализма в системе подготовки научных кадров.

Методология исследования. В рамках поставленной цуели автор опирается на трансдисциплинарную парадигму, базирующуюся на конвергенции знания и навыков различных областей профессиональной деятельности.

Результаты исследования. Феномен транспрофессионализма является адекватным современной эпохе с ее революиией в мире профессий, ее высочайшей динамикой инноваций и перемен. Однако для эффективного распространения этого явления в обществе, в профессиональной среде необходимы определенные условия, прежде всего, связанные с профессиональной подготовкой такого рода специиалистов, способных к полипрофессиональной деятельности и понимающих все перспективы именно транспрофессиональной подготовки.

Перспективы использования результатов исследования. Проблема транспрофессионализма уже привлекла внимание многих исследователей, но такая профессиональная группа, как ученье, еще не попала в оптику этого предметного поля. Результаты данного исследования могут использоваться для управленческих решений на всех уровнях власти.

Ключевые слова: молодежь; профессия; молодые ученые; транспрофессионализм; трансфессия; профессионализаџия; образование; рынок труда.

\section{TRANSPROFESSIONALISM IN THE SYSTEM OF PROFESSIONAL TRAINING AND ADAPTATION OF YOUNG SCIENTISTS IN A MOBILE WORLD}

\section{(C) 2020 O. S. Ivanchenko}

\section{Platov South Russian State Polytechnic University (NPI), Novocherkassk, Russia}

Purpose of the research. This article actualizes the problem of transprofessionalism in the system of training scientific personnel.

1 Статья выполнена в рамках реализации гранта Президента Российской Федерации для государственной поддержки ведущих научных школ Российской Федерации (НШ-2582.2020.6) на тему «Государственная политика в сфере высшего образования и развитие инновационного потенциала молодежи: экономические и неэкономические детерминанты и механизмы в условиях регионализации социального пространства и становления индустрии 4.0». 
Research methodology. Within the framework of this goal, the author relies on a transdisciplinary paradigm based on the convergence of knowledge and skills of various areas of professional activity.

Research result. The phenomenon of transprofessionalism is adequate to the modern era with its revolution in the world of professions, with its highest dynamics of innovation and change. However, for the effective dissemination of this phenomenon in society, in the professional environment, certain conditions are necessary, first of all, related to the professional training of such professionals who are capable of multiprofessional activities and understand all the prospects of transprofessional training.

Prospects for using the research results. The problem of transprofessionalism has already attracted the attention of many researchers, but such a professional group as scientists has not yet got into the optics of this subject field. The results of this study can be used for management decisions at all levels of government.

Key words: youth; profession; young scientists; transprofessionalism; transfession; professionalization; education; labor market.

Введение. В профессиональной сфере, как и в любой другой, в современном динамично меняющемся мире происходят значимые перемены. Их связывают с третьей профессиональной революцией, когда именно люди, способные выйти за пределы своей изначально выбранной и полученной в учебном заведении профессии, достигают вершин успеха, а узкоспециализированные профессионалы испытывают трудности в процессе адаптации к новым условиям рынка труда. Эти новые условия определяются тем, что появляются новые профессии, становятся невостребованными прежние, традиционные; меняются требования со стороны работодателей к специалистам, к молодым работникам; возрастает спрос на транспрофессионалов, готовых к постоянному профессиональному движению, профессиональному обновлению, получению новых профессиональных знаний и умений. «Привычные представления о развитии начинают рассыпаться на глазах: у отдельно взятого работника одновременно оказывается сразу несколько “траекторий развития" (“карьерных путей”), прочерчиваемых в одной или нескольких сферах деятельности» [1].

Сама система образования должна измениться. Она должна стать инструментом для проектирования учащимися, будущими специалистами, самих себя, причем на протяжении всей профессиональной жизни, что в науке получило название метапознания как умения управлять собственным обучением [2].
Однако возникает вопрос: в каждой ли сфере профессиональной деятельности можно стать транспрофессионалом? В каждой ли нужно им стать? Является ли это явление универсальным с точки зрения мира профессий? В данной работе мы хотим обратиться к молодым ученым, которые так же, как и представители других профессиональных сфер, оказались в сложных условиях рынка труда, адаптации к его динамичным изменениям и непростым экономическим реалиям российского общества.

Транспрофессионализм как предмет научных исследований. Прежде чем перейти к ответу на поставленные относительно молодых ученых вопросы в контексте такого явления, как транспрофессионализм, имеет смысл рассмотреть характер научного дискурса, развернувшийся относительно данного явления, которое в научном пространстве представлено также в виде трансфессионализма.

Транспрофессионализм как понятие, символизирующее глубинную трансформацию профессионализма, глобальную профессиональную революцию, переход к новым формам организации (самоорганизации) профессиональной деятельности, в том числе совместной [1], все чаще попадает в пространство научного дискурса. Данное явление рассматривается учеными как «готовность и способность осваивать и выполнять деятельность (действия) различных видов 
и групп профессий» [3]. Транспрофессионализм в науке получил разные названия: мультипрофессионализм, профессиональная многомерность, радикальный полипрофессионализм, но, как указывает А.Г. Кислов [4, с. 5457], важно то, что этот феномен стал чрезмерно востребованным и его эффективность зависит от того, какие две или более профессии осваиваются - смежные или далекие друг от друга. Именно освоение несмежных профессий дает эффект полипрофессионализма, и дело не только в расширении диапазона профессиональных возможностей, сколько в способности и готовности выйти за пределы своей профессии и сформировавшихся за время ее получения стереотипов.

Э.Ф. Зеер разводит понятия «трансфессия» и «транспрофессионализм»: под первым он понимает «вид трудовой активности, реализуемой на основе синтеза и конвергенции профессиональных компетенций, принадлежащих к разным специализированным областям», а под вторым - «способность к выполнению широкого радиуса специализированных видов деятельности», которая является профессионалогической характеристикой трансфессий [5, с. 47]. Особое значение транспрофессионализм, с точки зрения данного автора, имеет для профессий социономической направленности, ориентированных на изучение людей, разных общностей, социальных групп, социальных отношений и систем, и связанных со сферой управления, социального, медицинского, информационного обслуживания, правовой и социальной защиты. Методологической основой их деятельности с точки зрения транспрофессионализма выступает трансдисциплинарная парадигма, базирующаяся на конвергенции знания и навыков различных областей профессиональной деятельности, а в качестве инструментальных компонентов транспрофессионализма этого вида профессий Э. Ф. Зеер выделяет регулятивную, профессиональнообразовательную, информационно-коммуникативную, гуманитарно-технологическую компоненты и трансфессиональную направленность [5, с. 50].

«Транспрофессионалы - это люди, не привязанные к одной узкой специализации, которую получили в университете. Они обладают широкими знаниями и навыками в различных профессиональных областях за счет того, что активно занимаются саморазвитием, постоянно обучаются», а узкие специалисты, по мнению исследователей, обречены - «они нужны, но больше того, что имеют сейчас, получать не будут. Специализация хороша, когда учишься» [6]. И, видимо, стоит прислушаться к словам о том, что общество вступило в «эпоху так называемых транспрофессионалов - людей, подготовленных междисциплинарно, ориентирующихся на объект в целом, а не на какую-то одну его сторону» [7].

Наступление этой эпохи и распространение транспрофессионализма обусловлены самой реальностью с ее информационной революцией, цифровым взрывом. Меняется социально-профессиональная среда, трансформируется представление о профессии и профессионализации, а также о профессиональной и социальной мобильности.

В мире, в котором мобильность сама по себе есть критерий современности [8, c.197-252], человек должен стремиться отвечать этому критерию и, прежде всего, в профессиональной сфере, непрерывно развивая свои профессиональные навыки в парадигме трансдисциплинарности и межпрофессиональной коммуникативистики [3]. Соответственно, университеты, следуя мнению специалистов, должны стать другими, способными готовить специалистов будущего, т.е. транспрофессионалов или трансфессионалов, способных жить поверх профессиональных границ, менять профессию, меняться вместе с профессией, чтобы быть конкурентоспособными и профессионально успешными [2].

Раскрывая особенности подготовки трансфессионалов в условиях современной магистратуры, уже имеющей трансфессиональную направленность, В.И. Кабрин полагает, что для этого необходимо использовать методы коммуникативной креативности, творческой коммуникации и креативного лидерства в рамках синтеза холистического и ноэтического подходов [9].

Теперь от молодых специалистов, только приступивших к своей профессиональной деятельности, требуется не столько наличие приобретенных во время обучения в образовательном учреждении знаний и навыков, 
сколько готовность выйти за пределы своей профессии, быть профессионально многогранными, ориентированность на трансфессию и транспрофессиональную идентичность. Но готова ли система образования к подготовке такого рода профессионалов? Многие исследования говорят об обратном. В них отмечается значительный разрыв между образованием и рынком труда, низкая эффективность вузов в подготовке кадров [10, c. 114-122], отставание еще консервативной по своей сути российской системы образования от требований современной эпохи и изменений, происходящих в мире профессий, от передовых технологий в подготовке молодых специалистов, в том числе и в сфере научно-исследовательской деятельности [11, c. 323-326].

Молодые ученые в России: профессионализация, трансфессионализация или депрофессионализация? Многочисленные источники по проблеме профессиональной самореализации молодых специалистов в России убедительно показывают, что этот процесс характеризуется множеством проблем. Особенно актуально это для тех, кто впервые выходит на рынок труда [12, с. 95-105]. Число выпускников российских вузов, работающих по специальности, постоянно сокращается [10, с. 114-122]. По-прежнему остро стоит проблема интеллектуальной миграции среди молодежи, в том числе и той, которая выбрала для себя путь ученого [13, с. 60-68]. Этот путь очень непростой в российских условиях, в том числе в сравнении с мировыми университетами и особенностями организации в них исследовательской работы молодых ученых. Об этом пишут многие исследователи, приходя к выводу о дефиците как профессиональных ориентиров среди российских молодых ученых, так и ресурсов поддержки для качественной исследовательской работы [14, c. $144-154]$.

Надо сказать, что молодые ученые являются довольно специфической профессиональной группой, которую характеризуют иные механизмы профессионального выбора и формирования профессиональных предпочтений, а также необходимость государственной поддержки для реализации научно-исследовательской деятельности и про- фессионального роста, создания адекватных условий для такого рода профессиональной деятельности. Эти условия, судя по тому, что молодежь, приходя в науку, ненадолго задерживается в ней [15, с. 9-24], не созданы. Об этом говорит также небольшой процент заканчивающих аспирантуру с защитой диссертации [16, с. 87-108], а также тех, кто после этого остается в академической среде.

Таким образом, освоение новых видов профессиональной деятельности молодыми учеными зачастую связано с вынужденной мерой, со сложностями трудоустройства и закрепления в академической и научной сфере. А если учесть, что путь, который проделывают молодые ученые, приходящие в науку, мотивированные не столько материальными стимулами, сколько стремлением к самореализации [17, с. 187-198], жаждой оставить след в науке, очень непростой, предполагающий несколько ступеней образования (магистратура, аспирантура, докторантура), разрушенные профессиональные планы, надежды и перспективы данной профессиональной группой представляются более трагичными как для самих молодых специалистов, так и государства, которое выделяет на подготовку молодых ученых определенные финансовые ресурсы и нуждается в молодых научных кадрах.

Определенно, необходимо принимать меры, способствующие более эффективной адаптации молодых ученых в профессиональном поле, которое в научной сфере для профессионального роста и успеха в качестве обязательных элементов включает механизмы профессиональной мобильности. К ним относятся различные формы международного сотрудничества, интеграции в исследовательские коллективы, проекты, организации, участие в крупных российских и международных научных мероприятиях, в разработке перспективных научных направлений при помощи научных фондов и др. Для этого многое делается в зарубежных странах в рамках поддержки молодых ученых и их интеграции в научно-исследовательские сообщества, ассоциации, проекты. Также наши российские специалисты обращают внимание на такую положительную зарубежную практику, как регулярные мониторинги проблем, ожиданий, карьер- 
ных стратегий аспирантов, уровня их удовлетворенности образованием, условиями обучения и т.д., и призывают применять эту практику и в России [18, с. 89-97].

Пока же мы можем констатировать, что научная сфера в современной России развивается по кризисной траектории. Ее отличают низкий уровень финансирования со стороны государства, падение уровня академической культуры, невысокий престиж профессии ученого и преподавателя, снижение доли молодых в возрастной структуре российской науки, высокий уровень интеллектуальной миграции, в которой значительную часть составляет молодое поколение.

Сложности в профессиональной самореализации могут стать источником разочарования в профессии. Вероятность этого тем больше, чем больше надежд и перспектив связывалось с будущей профессией. Д.Л. Константиновский указывает на то, что разочарование в выбранной профессии настигает многих еще на уровне обучения в вузе по причине неоправдавшихся ожиданий от профессии и низкого качества образования $[19$, с. 160$]$, в результате чего происходит последующая смена профессии, а порой и череда подобных профессиональных «миграций». Однако, как правило, такая стратегия профессиональной адаптации не приводит к транспрофессионализму как профессиональному качеству, повышающему конкурентоспособность молодого специалиста, поскольку делается это стихийно, вынужденно, не в рамках специального профессионального самопроектирования, призванного повысить профессиональный статус личности до уровня трансфессионала.

Такая (незапланированная, вынужденная) профессиональная миграция может привести к формированию профессионального инфантилизма, когда утрачивается интерес к какой-либо профессиональной деятельности, а основной целью становится выживание на рынке труда и заработная плата. И в подобных случаях, просматривая риски повышенной динамики такого поведения в молодежной среде, исследователи говорят о депрофессионализации молодежи как одной из самых негативных тенденций современного российского общества $[20$, c. $88-94]$.
Заключение. В качестве ключевого вывода мы хотим обратить внимание на несколько позиций. Во-первых, сам феномен транспрофессионализма является адекватным современной эпохе с ее революцией в мире профессий, ее высочайшей динамикой инноваций и перемен. Однако для эффективного распространения этого явления в обществе, в профессиональной среде необходимы определенные условия, прежде всего, связанные с профессиональной подготовкой такого рода специалистов, способных к полипрофессиональной деятельности и понимающих все перспективы именно транспрофессиональной подготовки. Очевидно, российская система образования пока не готова к подготовке такого рода и уровня профессионалов, несмотря на формальное соответствие тем или иным формам обучения, в частности, в магистратуре, предполагающих формирование транспрофессионализма у молодых специалистов.

Во-вторых, проблема формирования транспрофессионализма у молодых ученых требует особого анализа в силу специфики самой профессиональной группы ученых, а также сложностей адаптации в академической и научной среде в кризисных реалиях образования и науки в России. В большинстве случаев молодыми учеными реализуется не стратегия транспрофессионализма при попытке выйти за пределы своей профессии, а смена профессии чаще всего вынужденного характера.

На этом основании можно заключить, что транспрофессионализм в российских реалиях профессионализации и рынка труда есть следствие, как правило, вынужденной стратегии профессионализации в рамках адаптации к неблагоприятным условиям рынка труда, а потому его следует рассматривать как искаженную форму профессионализации, граничащую с депрофессионализацией. И среди молодых ученых эта тенденция только возрастает.

\section{Литература}

1. Малиновский П. Транспрофессионализм как критерий эффективности управления человеческим потенциалом [Электронный pecypc]. - Режим доступа: http://www.shkp. $\mathrm{ru} /$ lib/actions/ss/malinovsky/publications/1. 
2. Субботина А. Как подготовить «трансфессионала» XXI века? [Электронный ресурс]. - Режим доступа: https://www.nkj.ru/ open/32497/.

3. Транспрофессионализм субъектов социально-профессиональной деятельности [Электронный ресурс]: монография / В.С. Третьякова [и др.]; под ред. Э. Ф. Зеера, В.С. Третьяковой. - Екатеринбург: Изд-во Рос. гос. проф.-пед. ун-та, 2019. - 142 с. Режим доступа: http://elar.rsvpu.ru/978-58050-0668-6.

4. Кислов А. Г. От опережающего к транспрофессиональному образованию // Образование и наука. - 2018. - Т. 20. - №1. C. 54-74.

5. Зеер Э. Ф. Методология развития транспрофессионализма субъектов социономических профессий // Образовательные технологии. - 2018. - №3. - С. 46-59.

6. Виноградова E. Транспрофессионалы - люди будущего? [Электронный pecypc]. - Режим доступа: http://www. uralstudent.ru/articles/career/2237349.

7. HR XXI века - транспрофессионалы наступают и выигрывают [Электронный pecypc]. - Режим доступа: https://hr-portal. ru/article/hr-xxi-veka-transprofessionalynastupayut-i-vyigryvayut.

8. Урри Дж. Мобильности // Мониторинг общественного мнения. - 2012. №5(111). - С. 197-252.

9. Кабрин В.И. Становление потенциала креативного лидерства трансфессионалов в образовательных пространствах магистратуры [Электронный ресурс] // Педагогика и просвещение. - 2019. - №4. - Режим доступа: https://nbpublish.com/library_read_ article.php?id $=30766$.

10. Зубок Ю.А., Чупров В.И. Молодые специалисты: проблема подготовки и положение на рынке труда // Социологические исследования. - 2015. - №5. - С. 114-122.

11. Чигишева О.П. Роль исследовательской грамотности в профессиональной деятельности ученого // Балтийский гуманитарный журнал. - 2018. - Т. 7. — №3 (24). C. 323-326.

12. Чередниченко Г. А. Положение на рынке труда выпускников вузов (по материалам опроса Росстата) // Социологические исследования. - 2018. — №11. - С. 95-105.
13. Ащеулова Н.А., Душина С.А. Академическая карьера молодого ученого в России // Инновации. - 2012. — №7 (165). - С. 60-68.

14. Другова Е.А., Андраханов А.А., Больбасова Л.А., Коричин Д.А. Профессиональный рост молодого ученого: дефицитные ресурсы поддержки // Университетское управление: практика и анализ. - 2017. — Т.21. №2. - С. 144-154.

15. Бедный Б.И., Миронос А.А., Рыбаков Н.В. Как российская аспирантура выполняет свою главную миссию: наукометрические оценки // Высшее образование в России. - 2019. - Т. 28. - №10. - С. 9-24.

16. Бекова С.К., Джсафарова 3.И. Кому в аспирантуре жить хорошо: связь трудовой занятости аспирантов с процессом и результатами обучения // Вопросы образования. 2019. - №1. - C. 87-108.

17. Душина С.А., Ломовиикая В.М. Социальные детерминанты карьеры молодых ученых в период реформирования российской науки (на материалах полевого исследования) // Социологический альманах. 2016. 一 №7. - С. 187-198.

18. Груздев И. А., Терентьев Е.А. Данные против мифов: результаты социологического исследования // Высшее образование в России. - 2017. — №7 (214). — С. 89-97.

19. Константиновский Д.Л. Новая молодежь в новой реальности образования // Образование и наука в России: состояние и потенциал развития. Сборник научных трудов. - М.: Центр социологических исследований, 2016. - С. 106-162.

20. Растегаева A.B. Депрофессионализация трудовых ресурсов в современной России // Вестник Поволжского института управления. - 2017. - Т. 17. - №3. - С. 88-94.

\section{References}

1. Malinovskij $P$. Transprofessionalizm kak kriterij jeffektivnosti upravlenija chelovecheskim potencialom [Transprofessionalism as a criterion for the effectiveness of human potential management] [Jelektronnyj resurs]. — URL: http://www.shkp.ru/lib/actions/ss/malinovsky/ publications/1.

2. Subbotina A. Kak podgotovit' «transfessionala» XXI veka? [How to prepare a «transmissional» of the XXI century?] [Jele- 
ktronnyj resurs]. — URL: https://www.nkj.ru/ open/32497/.

3. Transprofessionalizm subektov social'noprofessional'noj dejatel'nosti [Transprofessionalism of subjects of social and professional activity] [Jelektronnyj resurs]: monografija / V.S. Tret'jakova [et al.]; In Je. F. Zeer, V.S. Tret'jakova (eds.). — Ekaterinburg: Izd-vo Ros. gos. prof.-ped. un-ta, 2019. - 142 p. URL: http://elar.rsvpu.ru/978-5-8050-0668-6.

4. Kislov A.G. Ot operezhajushhego k transprofessional'nomu obrazovaniju [From advanced to transprofessional education] // Obrazovanie i nauka. - 2018. - Vol. 20. - №1. Pp. 54-74.

5. Zeer Je. F. Metodologija razvitija transprofessionalizma subektov socionomicheskih professij [Methodology of development of transprofessionalism of subjects of socionomic professions] // Obrazovatel'nye tehnologii. 2018. - №3. - Pp. 46-59.

6. Vinogradova E. Transprofessionaly - ljudi budushhego? [Transprofessionals - people of the future?] [Jelektronnyj resurs]. — URL: http:// www.uralstudent.ru/articles/career/2237349.

7. HR XXI veka - transprofessionaly nastupajut i vyigryvajut [HR of the XXI centurytransprofessionals come and win] [Jelektronnyj resurs]. — URL: https://hr-portal.ru/article/hrxxi-veka-transprofessionaly-nastupayut-i-vyigryvayut.

8. Urri Dzh. Mobil'nosti [Mobility] // Monitoring obshhestvennogo mnenija [Monitoring of public opinion]. — 2012. — №5 (111). Pp. 197-252.

9. Kabrin V.I. Stanovlenie potenciala kreativnogo liderstva transfessionalov v obrazovatel'nyh prostranstvah magistratury [Formation of the potential of creative leadership of transfessionals in the educational spaces of the magistracy] [Jelektronnyj resurs] // Pedagogika i prosveshhenie [Pedagogy and education]. — 2019. - №4. URL: https://nbpublish.com/library_read_article. php?id=30766.

10. ZubokJu. A., Chuprov V.I. Molodye specialisty: problema podgotovki i polozhenie na rynke truda [Young specialists: the problem of training and the situation on the labor market]// Sociologicheskie issledovanija [Sociological research]. — 2015. - №5. - Pp. 114-122.

11. Chigisheva O.P. Rol' issledovatel'skoj gramotnosti $\mathrm{V}$ professional'noj dejatel'nosti uchenogo [The role of research literacy in the professional activity of a scientist] // Baltijskij gumanitarnyj zhurnal [Baltic Humanitarian Journal]. — 2018. — Vol. 7. — №3 (24). Pp. 323-326.

12. Cherednichenko G.A. Polozhenie na rynke truda vypusknikov vuzov (po materialam oprosa Rosstata) [The situation on the labor market of university graduates (based on the materials of the Rosstat survey)] // Sociologicheskie issledovanija [Sociological research]. 2018. — №11. - Pp. 95-105.

13. Ashheulova N.A., Dushina S.A. Akademicheskaja kar'era molodogo uchenogo $\mathrm{v}$ Rossii [Academic career of a young scientist in Russia] // Innovacii [Innovations]. - 2012. №7 (165). - Pp. 60-68.

14.Drugova E.A.,Andrahanov A. A., Bol'basova L. A., Korichin D. A. Professional'nyj rost molodogo uchenogo: deficitnye resursy podderzhki [Professional growth of a young scientist: scarce support resources] // Universitetskoe upravlenie: praktika i analiz [University Management: Practice and Analysis]. — 2017. Vol. 21. - №2. - Pp. 144-154.

15. Bednyj B.I., Mironos A.A., Rybakov N.V. Kak rossijskaja aspirantura vypolnjaet svoju glavnuju missiju: naukometricheskie ocenki [How the Russian postgraduate school fulfills its main mission: scientometric assessments] // Vysshee obrazovanie v Rossii [Higher education in Russia]. — 2019. — Vol. 28. — №10. Pp. 9-24.

16. Bekova S. K., Dzhafarova Z.I. Komu v aspiranture zhit' horosho: svjaz' trudovoj zanjatosti aspirantov s processom i rezul'tatami obuchenija [To whom to live well in graduate school: the connection of employment of graduate students with the process and results of training] // Voprosy obrazovanija [The issue of education]. - 2019. — №1. - Pp. 87-108.

17. Dushina S. A., Lomovickaja V.M. Social'nye determinanty kar'ery molodyh uchenyh v period reformirovanija rossijskoj nauki (na materialah polevogo issledovanija) [Social determinants of the career of young scientists during the reformation of Russian science (on the materials of field research)] // Sociologicheskij al'manah. 2016. — №7. - Pp. 187-198.

18. Gruzdev I.A., Terent'ev E.A. Dannye protiv mifov: rezul'taty sociologicheskogo issledovanija [Data against myths: results of a so- 
ciological study] // Vysshee obrazovanie v Rossii [Higher education in Russia]. — 2017. №7 (214). — Pp. 89-97.

19. Konstantinovskij D.L. Novaja molodezh' $v$ novoj real'nosti obrazovanija [New youth in the new reality of education] // Obrazovanie i nauka v Rossii: sostojanie i potencial razvitija. Sbornik nauchnyh trudov [Education and science in Russia: state and potential of development. Collection of scientific papers]. -
Moscow: Centr sociologicheskih issledovanij, 2016. - Pp. 106-162.

20. Rastegaeva A. $V$. Deprofessionalizacija trudovyh resursov v sovremennoj Rossii [Deprofessionalization of labor resources in modern Russia] // Vestnik Povolzhskogo instituta upravlenija [Vestnik Povolzhskogo Instituta Upravleniya]. — 2017. - Vol. 17. — №3. Pp. 88-94.

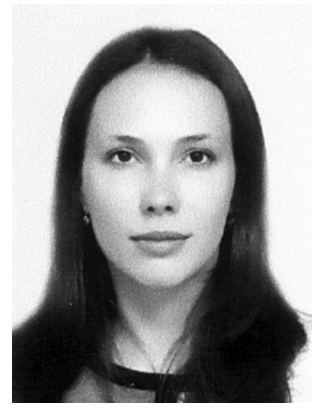

Иванченко Ольга Сергеевна - кандидат социологических наук, доцент Южно-Российского государственного политехнического университета (НПИ) имени М. И. Платова.

Ivanchenko Olga Sergeevna - Candidate of Sociological Sciences, Associate Professor, Platov South Russian State Polytechnic University (NPI).

346428 , г. Новочеркасск, ул. Просвещения, 132

132 Prosveshcheniya st., 346528, Novocherkassk, Russia

E-mail: olga.ivanchenko1509@mail.ru 